\title{
La reflexión sobre el género en Platón: un pensamiento ontológico acerca de la identidad y la diferencia
}

\section{The Reflection on Gender in Plato: An Ontological Thought on Identity and Difference}

\author{
Jeannet Ugalde Quintana \\ Universidad Nacional Autónoma de MÉxico
}

\section{Resumen}

La filósofa Simone de Beauvoir fue una de las primeras en observar y criticar, dentro de los discursos filosóficos, planteamientos de tipo monista en los cuales lo femenino se presenta como ausencia o negatividad. Sin embargo, en Platón encuentro trazos de una visión ontológica que escapa a una determinación monista o dualista del Ser y que permite comprender el género, desde la igualdad y la diferencia.

Palabras clave: Platón, género, ontología, definición, ser

\begin{abstract}
Philosopher Simone de Beauvoir was one of the first to observe and to criticize, within philosophical discourses, monistic approaches from which the feminine presents itself as absence or negativity. However, in Plato, I find traces of an ontological vision that escapes a monistic or dualistic determination of Being and allowing an understanding of gender in terms of equality and difference.
\end{abstract}

Keywords: Plato, gender, ontology, definition, being 
Durante las últimas décadas los estudios de género se han colocado en un lugar primordial. Tras la puesta en cuestión de una visión naturalista o economicista del género, se ha desvelado su carácter social e histórico. De este modo, Bourdieu en su escrito La dominación masculina considera que de la misma manera que toda clasificación, la división que se ha establecido entre los "seres humanos" según su sexo, encuentra justificación en una ordenación de las cosas. Empero, esta clasificación se ha naturalizado en nuestras sociedades y se puede observar en la forma de percibir las cosas y de actuar, hasta el punto de considerarla algo objetivo que no requiere ser cuestionado. Al mismo tiempo, este esquema de percepción basado en la división de sexos ha establecido lo "masculino" como dominante y lo "femenino" como lo dominado.

La división entre los sexos parece estar "en el orden de las cosas", como se dice a veces para referirse a lo que es normal y natural, hasta el punto de ser inevitable: se presenta a un tiempo, en su estado objetivo, tanto en las cosas (en la casa por ejemplo, con todas sus partes "sexuadas"), como en el mundo social y, en estado incorporado, en los cuerpos y en los hábitos de sus agentes, que funcionan como sistemas de esquemas de percepciones, tanto de pensamiento como de acción. (Bourdieu, 1999: 10)

En este esquema de ordenación, Bourdieu observa una dominación "androcéntrica" que se presenta como neutral y que por ello no requiere de ningún tipo de discurso justificatorio; de forma común y natural, "lo masculino" tiene un aspecto de dominación y privilegio frente a "lo femenino". Sin embargo, esta estructura de dominio se hace evidente en lo cotidiano a partir de la división diferenciada del sexo, según actividades y deberes sociales en ámbitos como el trabajo, la participación social, los lugares de reunión y los ciclos de vida.

Este carácter "androcéntrico" de nuestras sociedades fue observado de forma muy clara en el discurso filosófico por la pensadora Simone de Beauvoir. En el escrito El segundo sexo, Beauvoir expresa su interés por abordar la cuestión de ¿qué es la mujer?, una pregunta que encuentra irritante al no haber sido considerada como objeto de análisis, dentro de la filosofía, por ninguna figura masculina. Definir qué es una mujer se encuentra con una primera problemática: ¿̇e qué manera distinguir entre un "ser humano hembra" y participar de la "feminidad"? Tradicionalmente, la mujer ha sido definida como un "ser humano" (homo), sin embargo este término también se traduce como "hombre". El concepto homo puede referir al "ser humano macho" o nombrar a aquel que participa de la "masculinidad", por ello, la definición de la mujer a partir de este concepto resulta 
problemática. En este sentido, Beauvoir considera que la tematización acerca de la "mujer" se ha presentado en la filosofía de la siguiente manera: como una omisión o ausencia a partir de una visión negativa de "lo femenino" frente a lo "masculino".

Reflexionar sobre ¿qué es la mujer? ha parecido una tarea innecesaria para la filosofía, debido a que se ha considerado que "mujer" es un concepto que se encuentra presente en la noción de "homo sapiens" (ser humano) y que por lo tanto no requiere una tematización. Por otra parte, Beauvoir afirma que aquellos filósofos que han hablado de forma acotada sobre qué es una mujer, la han definido en relación con el hombre a partir de sus diferencias corporales, que la hacen aparecer como un "ser humano" caracterizado por la ausencia de objetividad y perfección. Para los filósofos, la mujer ha representado la concreción de una falta ontológica, todo aquello que "el hombre" no es:

La mujer es mujer en virtud de cierta falta de cualidades — decía Aristóteles—. Y debemos considerar el carácter de las mujeres como adolesciente de una imperfección natural.” Y, a continuación, Santo Tomás decreta que la mujer es un "hombre fallido", un ser "ocasional”. Eso es lo que simboliza la historia del Génesis, donde Eva aparece como extraída, según frase de Bossuet, de un "hueso supernumerario" de Adán. (De Beauvoir, 2016: 18)

Así, para Beauvoir la definición de "la mujer" se ha realizado en dependencia de lo que es el "hombre" y de forma negativa. "La mujer" representa lo "Otro", pero un "Otro" carente de objetividad y de determinaciones propias y autónomas, mientras que lo masculino está provisto de sentido y determinación esencial.

La crítica que realiza Simone de Beauvoir a la filosofía recorre desde Aristóteles hasta Michelet y encuentra sustento en planteamientos ontológicos de tipo monista en los cuales existe una representación del concepto de lo "otro" como vacuidad.

Considerando esta crítica a la filosofía que lleva a cabo Simone de Beauvoir, la cual me parece muy pertinente, en las páginas que presento a continuación exploro la noción de género (génos) a partir de Platón. En el filósofo ateniense encuentro trazos de una visión ontológica, que escapa a una determinación monista o dualista del Ser, planteamiento que abre la posibilidad de comprender las divergencias de género desde la igualdad y la diferencia. De esta manera, pienso que a partir de la comprensión ontológica planteada por Platón, del Ser en cuanto multiplicidad, es posible una interpretación no-dualista de la noción de género.

En un primer momento, a partir de un análisis de los diálogos Fedro, Banquete y Sofista, presento los diferentes significados del concepto génos en Platón. A partir de este estudio trato de mostrar que el concepto de génos mantiene algunas 
relaciones con la noción de eidos e idea, conceptos claves para la interpretación de lo existente y para la articulación de la noción de Ser. Posteriormente, una vez presentada la lectura del fragmento de Parménides sobre el Ser, que es abordado en el diálogo Sofista, ${ }^{1}$ intentaré desarrollar un vínculo con el diálogo Banquete, específicamente con el mito del "andrógino" que aparece en este diálogo. La comprensión del Ser en el Sofista es desarrollada a través del análisis de los distintos géne (géneros) del Ser. La reflexión de Platón sobre los diferentes géne del Ser, encuentra su origen en el planteamiento parmenideo del Ser, y en las nociones de unidad y multiplicidad.

En el fragmento parmenídeo sobre el Ser (Kirk, Raven y Schofield, 1977: "Parménides", fr. 8, 32-48), éste es descrito, en cuanto unidad, como una esfera. La imagen de la esfera se encuentra plasmada también en el Banquete. Aristófanes, al hablar de la naturaleza originaria de los seres humanos, considera que el cuerpo de éstos era en su totalidad circular, semejante a la esfera parmenídea. A partir de estas dos imágenes y de lo dicho por Platón en relación con el Ser en el Sofista y sobre la naturaleza de los seres humanos en el Banquete, plantearé una lectura según la cual el género en Platón es múltiple y escapa a una visión de dominio y dependencia. Si bien en esta mirada sobre el género se encuentran presentes conceptos que nos hablan de la igualdad y la diferencia, la comprensión que encuentro en Platón excede una formulación dual de dominio y dependencia de lo Uno frente a lo Otro.

Génos aparece en Platón a lo largo de toda su obra: Fedón, ${ }^{2}$ Crátilo, ${ }^{3}$ Teeteto, Sofista, Politico, Parménides, Filebo, Banquete, Fedro, Alcibiades, Cármides, Eutidemo, Protágoras, Hipias mayor, República, Timeo, Critias y Leyes, aunque se encuentra de forma más recurrente en los diálogos considerados como tardíos, entre ellos, en Timeo $^{4}$ y Leyes. ${ }^{5}$

El uso que Platón hace del concepto génos a lo largo de sus diálogos está relacionado con la forma de discusión propia de sus escritos, la cual está plasmada desde los diálogos de juventud. En los diálogos primeros se hace patente el interés de Platón por acceder al qué es de las cosas, esto es, a su definición. Esta forma de aproximación a los problemas permanecerá a lo largo de toda su obra y será raíz de su formulación de la teoría de las ideas. La pregunta por el qué, como búsqueda de

\footnotetext{
${ }^{1}$ Platón, Sofista, $244 \mathrm{e}$.

2 Platón, Fedón, \$\$82b10, 87c2.

${ }^{3}$ Platón, Crátilo, $\$ \$ 392 c 8,297 \mathrm{e} 8,397 \mathrm{e} 12$.

${ }^{4}$ Platón, Timeo, \$52a8, 53a6, 57a1, 59a8, 59b2, 59c2, 59e6, $60 \mathrm{~b} 4$.

${ }^{5}$ Platón, Leyes, $\$ \$ 629 d 4,645 a 7,653 d 1,677 a 6,677$ e10, 679b3, 680d8, 681a9.
} 
la definición, será explícitamente formulada posteriormente por Aristóteles, quien tras analizar los elementos de la definición, distinguirá género de especie. ${ }^{6}$

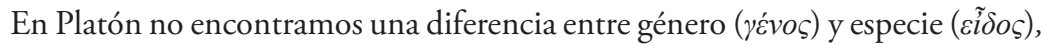
ambos conceptos son clasificatorios y le permiten elaborar una definición de las cosas. La diferencia entre género y especie, como lo sugiere Chernis en El enigma de la primera academia, es propia de Aristóteles (Chernis, 1993). Platón hace uso de este concepto y de la noción de eidos en un mismo sentido cuando intenta aclarar qué son las cosas. Así, génos va a estar vinculado con las nociones de idea y eidos. Además de idea, eidos y génos, Platón utilizará también el término moríon que significa parte, porción, sección o miembro cuando quiere dividir las partes que componen el todo de la definición.

Los conceptos eidos e idea se derivan del verbo griego idein (i $\delta \varepsilon \tilde{\imath} v)$ que significa "ver" o "forma visible". Algunos estudiosos de estos conceptos en Platón como Taylor (Taylor, 1911: 178) —quien realizara un estudio del uso de estas nociones en el siglo IV y V en la ciencia, la literatura y los escritos históricos-, ha concluido que eidos en Platón guarda una relación con el uso del concepto a partir de la escuela pitagórica en la cual estos conceptos designaban la figura o cuerpo geométrico en el sentido de la "esencia real" de algo, mientras que algunos otros intérpretes de Platón, como H.C. Baldry, mantienen que el uso de las nociones de eidos e idea en Platón es resultado de una combinación de la visión socrática de las virtudes que apunta a una comprensión de lo universal, con la concepción pitagórica de los números, de tal manera que ambas tradiciones repercuten en la formulación de la llamada teoría de las ideas en Platón (Ross, 1993: 29-30).

Hemos encontrado que la concepción de una "esencia real", y el uso de los nombres eidos, idea, sxema, morphe para denotarla, era común antes del fin del siglo $\mathrm{V}$ en cualquier parte donde la influencia del pitagorismo, transformada por la especulación de Empédocles, se hizo sentir; y suponer que el admirador de Filolao, el íntimo amigo de Cebes, Simias, Fedón y Equécrates, no sabía nada de tal doctrina, es cometer un palpable absurdo. Exactamente, qué papel desempeñó Sócrates en el desarrollo del pitagorismo y el eleatismo platónico, probablemente nunca lo sabremos, yo he tratado de mostrar una conjetura sobre este tema. (Taylor, 1911: 266)

En este sentido, el estudio que realiza David Ross sobre los conceptos de eidos e idea comienza con los seis sentidos que presenta Ritter en su escrito Neu Untersuchen dedicado a los significados de estos términos en Platón. Para Ritter, eidos e

${ }^{6}$ Aristóteles, Tratados de lógica (Organon) II, Analiticos Segundos, II, \$98a 1-25. 
idea nombran: 1) la apariencia externa; 2) la constitución o condición; 3) la característica que determina el concepto; 4) el concepto mismo; 5) el género o especie; y 6) la naturaleza objetiva que subyace al concepto. Ross concluye que eidos e idea en Platón mantienen el sentido original del término de "forma visible", aunque muchas veces serán usados en un sentido no técnico. Por otra parte, afirma que en algunas ocasiones este concepto presenta un significado formal de "clase", mientras que en otros contextos hace uso de los conceptos de ousia, physis, génos, énas y monás para referirse a la idea.

Respecto al uso que hace Platón de ambas palabras, eidos e idea, podemos decir: primero, tienen no pocas veces el significado original de "forma visible"; segundo, las usa en los diversos sentidos no técnicos que también encontramos en escritores anteriores; tercero, tiene el sentido técnico de "idea" y "clase". (Ross, 1993: 31)

Otro estudio importante sobre los diferentes sentidos de eidos e idea es el desarrollado por Monique Dixsaut en su artículo "Lidée du bien à sa lumière"(Disxaut, 2013: 67-86). En este escrito Dixsaut afirma que estos dos términos en Platón presentan una sinonimia; ambos nombran el "aspecto" general en el que algo se presenta, al mismo tiempo que el "aspecto físico". En su artículo destaca el hecho de que eidos nombra la articulación de dos realidades en oposición, por una parte nombra las entidades permanentes, las entidades ideales que tienen una existencia independiente $y$, por otra parte, se refiere a las entidades sensibles, caracterizadas por encontrarse en continuo devenir y cambio. En algunos pasajes como Fedro, ${ }^{7}$ Teeteto, ${ }^{8}$ Sofista, ${ }^{9}$ y Politico,,${ }^{10}$ eidos e idea parecen tener el mismo significado que génos. Para Dixsaut, el término eidos en Platón es un concepto complejo que tiene distintos sentidos; con él es posible nombrar: a) el aspecto sensible, b) la figura, c) la especie o el género y d) la forma inteligible.

De esta manera, el concepto género (génos) se encuentra relacionado en Platón con la definición y el estudio de la dialéctica. En el Sofista,${ }^{11}$ el Extranjero afirma que es propio de la dialéctica dividir por géneros y no considerar que una misma forma (eidos) es diferente, ni que una forma (eidos) diferente es la misma. El primer

\footnotetext{
${ }^{7}$ Platón, Fedro, $237 \mathrm{~d} 6$.

${ }^{8}$ Platón, Teeteto, $184 \mathrm{c} 4$.

${ }^{9}$ Platón, Sofista, $232 \mathrm{~d} 2$.

${ }^{10}$ Platón, Político, 289b4.

${ }^{11}$ Platón, Sofista, 253d.
} 
proceder de la dialéctica es el elenkhos (refutación). Este primer momento desvela la vinculación que guarda con la mayéutica socrática y la definición.

La estructura del elenkhos ha sido estudiada por G. Vlastos en "The socratic helenchus", quien considera que este primer momento del proceder dialéctico consiste en examinar las opiniones de los interlocutores a partir de cuestionamientos, sin tomar ninguna posición al respecto, de tal suerte que a partir de la formulación de preguntas se muestre, de manera imparcial, la incoherencia o contradicción en la que está incurriendo el interlocutor (Vlastos, 1982: 711-714). Este proceder, si bien es propio de la mayoría de los diálogos de Platón, lo vemos de manera clara en República VI y VII.

El elenkhos en cuanto primer elemento de la dialéctica guarda una cercanía con la mayéutica: se cuestiona al otro para ayudarle a liberarse del conocimiento (doxa) que cree tener para que pueda acceder al conocimiento (episteme). Este primer elemento de la dialéctica parece implicar un conocimiento previo de aquello que se pregunta, pues de este preguntar se espera un determinado tipo de respuesta que se considera el más adecuado.

Comprendida en su carácter metódico, la dialéctica contiene además dos momentos estructurales esenciales que permiten la definición. Estos momentos son la sinagogé y la diaíresis. La primera operación de la dialéctica es la sinagogé, que consiste en presentar la cosa que se desea mostrar como una unidad, de tal manera que después de este momento se puedan distinguir las partes o momentos que la componen. La segunda operación metódica de la dialéctica es la diairesis, la cual consiste en descomponer en las partes estructurales el fenómeno que ha sido contemplado de manera unitaria, teniendo como orientación la unidad primaria en la que la cosa se presentó. Este segundo momento sólo es posible teniendo como base la visión de la unidad originaria de la cosa en cuestión. De esta manera, la dialéctica será el método que permitirá el descubrimiento de las ideas en cuanto que unidad gracias a la sinagogé, pero al mismo tiempo, este método filosófico posibilita la observación de las distintas partes que componen la unidad gracias a la diaíresis. Por lo tanto, la reflexión en torno a los géneros en Platón corre paralelo al proceder de la dialéctica, pues ella es la que permite su observación.

Este proceder dialéctico es visible de forma clara en el modo en que ocurre el desvelamiento de los géneros, tanto en el caso del Sofista, que presento más adelante, en el cual se discute acerca de los distintos géneros del Ser, así como en el Banquete, donde Aristófanes discurre en torno a la naturaleza humana. A continuación presento algunos pasajes en los que Platón hace uso de génos y del sentido que le brinda. 
En Fedón, ${ }^{12}$ Platón distingue de entre las cosas que existen aquellas que son perdurables Al hablar de los distintos tipos de cosas, nuestro filósofo hace uso del concepto génos. Platón se pregunta entonces cuáles de los distintos géneros de cosas que hay son más perdurables. Entre ellas, considera dos posibilidades: un hombre o un manto que se encuentra en uso: "Y, si uno desconfiara de eso, le preguntaría si es más duradero el género de un hombre o el de un manto que está en uso y lo llevan” (Fedón, \$87c2). ${ }^{13}$ Por otra parte, Platón utiliza en Fedro ${ }^{14}$ el concepto género refiriéndose a los distintos tipos de discurso que se pueden elaborar. En este fragmento, Sócrates afirma que antes de ser capaz de acceder a la verdad es necesario definir cada cosa y dividirla en sus partes, de tal manera que gracias a este proceso sea posible acceder al conocimiento de las cosas en su naturaleza. Es así que la definición se presenta como un modo de acceso necesario al qué es de las cosas: "Antes de que alguien vea la verdad de aquello sobre lo que habla o escribe, y llegue a ser capaz de definir cada cosa en sí y, definiéndola, sepa también dividirla en sus especies hasta lo indivisible" (Fedro, \$277b-c). ${ }^{15}$

Ahora bien, en el Banquete, el concepto génos está en relación con el mito del andrógino. En boca de Aristófanes, Platón introduce los diferentes tipos de atracción y unión sexual que se dan entre los seres humanos a partir de un relato mítico, con el cual afirma que la naturaleza humana, desde tiempos antiguos, consta de tres géneros. A este mito me referiré más adelante.

Por otra parte, en el diálogo Sofista el concepto génos se encuentra presente en la investigación que busca esclarecer la actividad del filósofo, la del sofista y la del político. Después de que Teodoro afirmó que el filósofo es un ser divino, Sócrates se cuestiona cómo distinguir este género de hombres, los filósofos, de otros que realizan actividades semejantes y que presentan el mismo aspecto, como los sofistas y los políticos. Así, considera que dado que hay tres nombres distintos, aunque parecen realizar la misma actividad, existen tres géneros diferentes. El filósofo se distinguirá por relacionarse con la forma del Ser y mirar a lo divino. A partir de una frase de Parménides, Platón comienza a diferenciar al filósofo del sofista: "Que esto nunca se imponga -dice- que haya cosas que no son. Tú al investigar aparta el

\footnotetext{
12 Platón, Fedón, 87c.

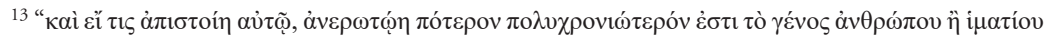

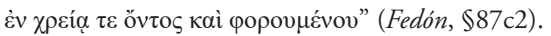

${ }^{14}$ Platón, Fedro, 277c.

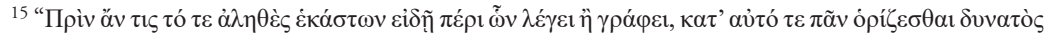

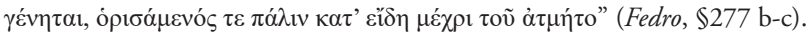


pensamiento de este camino” (Sofista, \$237a). ${ }^{16}$ El sofista será aquel que observa, a diferencia del filósofo, lo que no es. Platón encuentra la mirada puesta en lo que es y en su investigación en los filósofos antiguos al considerar que todos ellos se ocuparon de lo que es. Entre ellos distingue cuatro concepciones en torno al Ser: el Ser en cuanto triple, el Ser dual, el Ser uno, el Ser como múltiple y uno.

Uno dice que los entes son tres, que a veces pelean entre sí, y que otras veces, convertidos en amigos, llevan a cabo casamientos y nacimientos, y alimentan a sus descendientes. Otro dice que son dos, lo húmedo y lo seco, o lo caliente y lo frío, que cohabitan y se casan. El grupo eleata que partió de nosotros y que comenzó con Jenófanes y antes aún, expone en sus mitos que la llamada multiplicidad no es sino un solo ente. Luego, ciertas Musas de Jonia y de Sicilia pensaron que era más fácil combinar ambos mitos y decir que el ser es múltiple y uno, pues el odio y la amistad lo unen. (Sofista: $242 \mathrm{c}-\mathrm{d})^{17}$

Ante los distintos planteamientos acerca del Ser, Platón hace uso del personaje del extranjero para plantear la idea de la unidad del Ser.

El extranjero cuestiona a Teeteto qué nombra la palabra "Ser" y qué quieren decir quienes sostienen que todo es uno. Inicia la argumentación considerando la relación entre el nombre y el Ser. Así, considera que si "Ser" es un nombre, el nombre "Ser" nombra "lo que es". Al mismo tiempo si "lo que es", es uno, parece ser absurdo considerar la existencia de un nombre, debido a que el nombre "Ser" y lo que nombra "lo que es", son dos cosas. Sin embargo, considera las distintas posibilidades de argumentación a favor de la unidad: o bien el nombre y "lo que es" son lo mismo, o bien el nombre es nada y "lo que es" es uno, o bien el nombre se nombra a sí mismo y a ninguna otra cosa, siendo él "lo que es".

Debido a la oscuridad que representa hablar de la unidad del Ser y explicar en qué sentido "lo que es" puede ser uno, Platón recurre a una imagen más que a una argumentación. Así, presenta el fragmento 8 del poema de Parménides, en el cual se describe el Ser como una esfera redonda e idéntica del centro hacia todas direc-

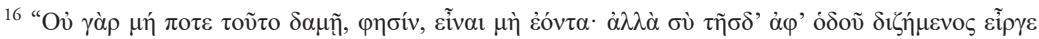
vón $\mu \alpha ”$ (Sofista, \$237a).

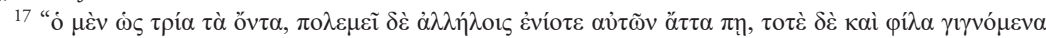

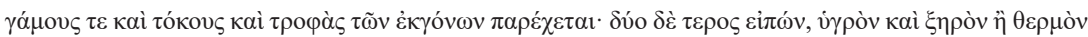

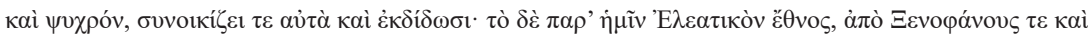

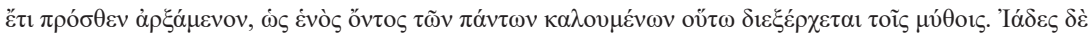

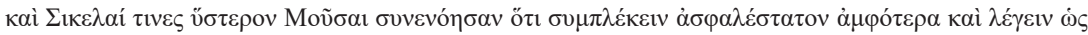

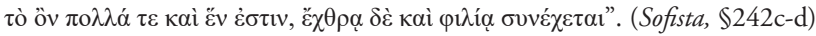


ciones, siendo ella una totalidad. ${ }^{18}$ Es por ello por lo que Platón considera que Parménides comprende el Ser ( $\tau$ ò òv $)^{19}$ a partir de la imagen de una esfera como una totalidad ( $\tau$ ò ö $\lambda$ ov), cuya perfecta redondez la hace igualmente poderosa en todas sus direcciones. La esfera tiene un punto medio y límites. El punto medio y los límites determinan que la esfera tenga partes, en este sentido la esfera en sus distintas direcciones presenta una totalidad compuesta de elementos. De esta manera, la discusión llega a la aporía de si lo que está dividido en partes posee la característica de la unidad y por lo tanto también es uno o lo que es uno es necesariamente indivisible. Al final de la discusión se distingue entre la unidad y lo uno, de tal manera que se abre paso al estudio de los géneros de lo que es, de tal manera que si bien los géneros conforman una unidad, ellos no son uno.

A partir de la esfera parménidea el Ser ( lidad ( se encuentra afectado no por unidad, no es uno, es descrito como una totalidad compuesta de distintos elementos. Los distintos elementos que lo componen, conforman lo que se denomina unidad. El Ser es una unidad total, sin se por ello Uno (Teeteto, $\$ 205 \mathrm{~d}) .{ }^{20}$

Esta misma discusión del Ser como unidad compuesta por partes la encontramos en el pasaje Teeteto, ${ }^{21}$ en relación con el tema de los primeros principios y elementos. Al cuestionarse acerca del Ser a Platón le interesa, por una parte determinar si la unidad está compuesta de partes; en un segundo momento, precisar si para conocer la unidad es necesario conocer las partes o géneros que la componen para, a partir de ello, definir cuál es la relación en la que se encuentra el todo con las partes que componen la unidad, debido a que de esto depende el conocimiento de los principios. Si el compuesto es cognoscible y explicable, también lo serán

18 "Semejante por doquier a la masa de una esfera bien redonda, absolutamente equidistante a

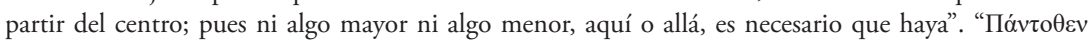

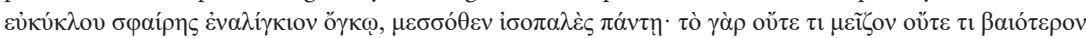

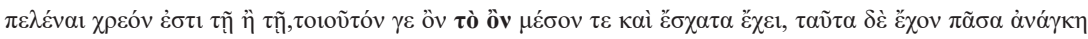

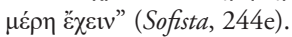

${ }^{19}$ Conviene aclarar que en el fragmento 8 del poema de Parménides, el concepto a partir del cual se refiere al Ser es tò eòn, pero en la cita de Platón sobre Parménides se presenta el concepto tò òn.

20 "Extr. - Pero nada impide que lo que está dividido posea, además de todas sus partes, la característica de la unidad, y que, siendo así completo y total, sea también uno.

Teet. - ¿Por qué no?

Extr. - Quizá sea necesario afirmar, según una argumentación correcta, que lo que es verdaderamente uno, es completamente indivisible."

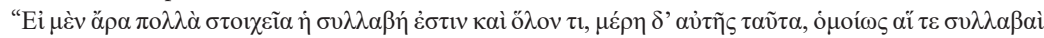

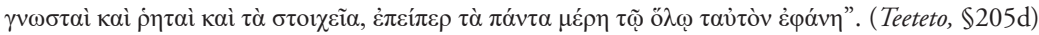

${ }^{21}$ Platón, Teeteto, 205a. 
las partes o elementos que lo componen. Las partes que componen el todo son entendidas como principios. Si el todo es cognoscible, también lo son los primeros principios de todas las cosas, "por consiguiente, si el compuesto es una pluralidad de elementos y un todo cuyas partes son los elementos, los compuestos han de ser tan cognoscibles y expresables como los elementos, dado que la totalidad de las partes parece ser lo mismo que el todo" (Teeteto, 205d). ${ }^{22}$

Esta representación del Ser en cuanto esfera, propuesta por Parménides, la encontramos nuevamente en la interpretación del "ser humano" que Platón presenta en el Banquete. Este diálogo ha sido considerado como uno de los escritos más acabados de Platón.

$\mathrm{Al}$ inicio del diálogo Banquete aparece Apolodoro, quien sin haber estado presente en la reunión en donde se discutió la naturaleza del amor, cuenta lo que le fue trasmitido por Aristodem. El papel narrarivo de Apolodoro en el diálogo Banquete desvela una caracterísitca del discurso dialógico, todo diálogo involucra al mismo tiempo un "habla" y un "escucha".

Así, Apolodoro escuchó de Aristodemo lo ocurrido en la reunión que tuvo lugar en la casa de Agatón. El tema de la reunión fue aquel que entre amigos resultó el más familiar, el amor. Sin embargo, la aproximación al amor no se dio por una búsqueda o definición de qué es el amor, sino a partir de la divinidad que nombra el impulso amoroso, eros.

De esta manera, la temática del diálogo permite crear relaciones con el Fedro. En ambos escritos eros aparece como la figura divina más antigua gracias a la cual se tematiza acerca de los principios primeros y el origen de todas las cosas.

Sobre el nacimiento de Eros, Fedro, presente en el Banquete, es el primero que toma la palabra para expresar el carácter prioritario de Eros. Así afirma que ningún dios le antecede, de tal manera que, como Hesíodo lo considera, es la divinidad primera, causa de movimiento y generación de todas las cosas, al mismo tiempo que responsable de los mayores bienes para los seres humanos. Esta última idea se pone en cuestión a partir de los discursos de Pausanias y Erixímaco quienes plantean un doble carácter de Eros. Tras estos discursos y la puesta en cuestión del carácter unívoco del dios, Aristófanes, el gran comediante griego, inicia un discurso cuyo interés es revelar su grandeza y poder.

Aristófanes se remonta a los orígenes en los que la palabra sólo puede ser expresada como narración de un pasado al que todos pertenecemos. Para explicar la

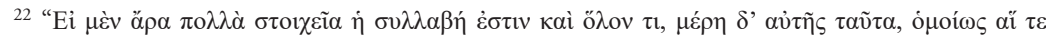

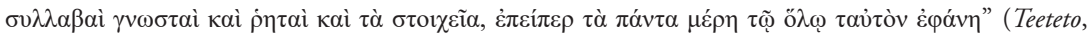
205d). 
importancia de eros considera que es necesario aclarar en qué consiste la naturaleza humana. ${ }^{23}$

Así, refiere a un tiempo antiguo, el tiempo en el que se inserta el discurso mítico, en donde la naturaleza humana era distinta a la actual. La diferencia de los seres humanos, anteriores a los actuales, comenzaba por su sexo. Los sexos de las personas no eran dos, como actualmente; sino tres: mujer, hombre y andrógino. A partir de esta primera diferencia, Platón establece una relación entre el ámbito de lo humano, del cosmos y del Ser. A cada sexo correspondía un planeta distinto, la tierra a lo femenino, el sol a lo masculino y la luna a lo andrógino. El ser humano encuentra un ámbito de unidad y pertenencia a ciertos caracteres supracelestes. Al mismo tiempo, aunque el ser humano en tanto idea es una unidad, esta unidad es múltiple y se encuentra compuesta de tres géneros distintos como una totalidad.

Aristófanes continúa con la descripción; de ella me gustaría hacer una observación que considero relevante: entre los géneros de los seres humanos propuestos por el mito del andrógino y la caracterización de Parménides sobre el Ser existe una vinculación. Los seres humanos tal como son descritos, son como la esfera parmenídea del Ser, redondos en su totalidad. El andrógino al mismo tiempo que participa de la unidad, contiene lo otro. ${ }^{24}$

El mito nos presenta una naturaleza triple, que hace que los seres humanos en sus tres distintos géneros sean lo mismo, pero al ser sólo una parte cada uno de ellos del género de lo humano, cada parte es distinta. La diferencia entre los distintos géneros del ser humano, tal cual es descrita por Platón no implica un predominio o supremacía de uno frente al otro. Todos ellos son en sus diferencias parte de lo que es. Los géneros del ser humano se encuentran, como la esfera parmenídea,

23 “[I] ntentaré, pues, explicaros su poder y vosotros seréis los maestros de los demás. Pero, primero, es preciso que conozcáis la naturaleza humana y sus modificaciones que ha sufrido, ya que nuestra antigua naturaleza no era la misma de ahora, sino diferente."

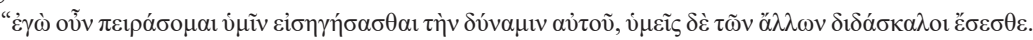

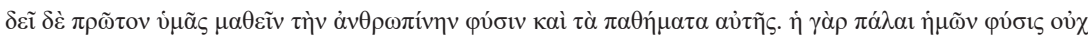

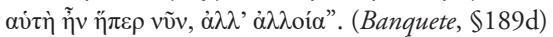

24 "En primer lugar, tres eran los sexos de las personas, no dos, como ahora, masculino y femenino, sino que había, además, un tercero que participaba de estos dos, cuyo nombre sobrevive todavía, aunque él mismo ha desaparecido. El andrógino, en efecto, era entonces una cosa sola en cuanto a forma y nombre, que participaba de uno y de otro, de lo masculino y de lo femenino, pero ahora no es sino un nombre que yace en la ignominia. En segundo lugar, la forma de cada persona era redonda en su

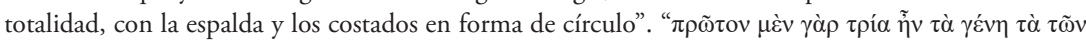

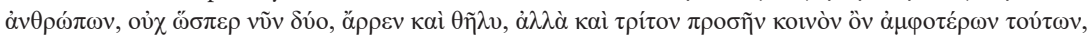

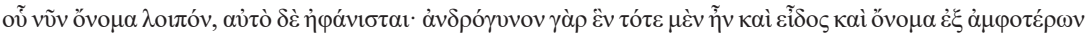

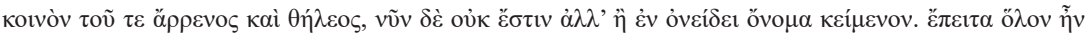

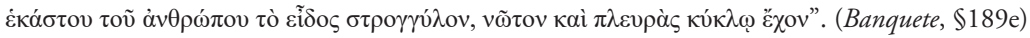


en una relación equidistante con respecto al centro. Al mismo tiempo el mito del andrógino no se inserta en la visión dualista, dominante en occidente, para la cual los géneros de lo humano son dos y se encuentran determinados por su sexo, sino que su género es triple y se explica por aquello a lo que tienden sus deseos y actitudes, los cuales a su vez están interrelacionados con el cosmos y con lo que es, con la totalidad.

Así, para Platón cada uno de nosotros es un símbolo, un fragmento del Ser, que al mismo tiempo es una totalidad y como tal, aspiramos a lo que pertenecemos, a lo Otro, a lo que es.

Cuantos hombres son sección de aquel ser [andrógino] son aficionados a las mujeres [...] proceden también de él cuantas mujeres son aficionadas a los hombres. Pero cuantas mujeres son sección de mujer, no prestan mucha atención a los hombres, sino que están más inclinadas a las mujeres, y de este género proceden también las lesbianas. Cuantos, por el contrario, son sección de varón, persiguen a los varones. (Banquete, $\$ 191 \mathrm{~d}-\mathrm{e})^{25}$

De esta manera, en Platón encontramos una reflexión ontológica en torno a la noción de género, a partir de la cual se abre la posibilidad de entender las diferencias en el ámbito de lo humano. Estas diferencias exceden una mirada dualista característica de los discursos filosóficos, en los que lo femenino representa la negatividad. En Platón la naturaleza humana es triple: lo femenino, lo masculino y lo andrógino forman una unidad en su diferencia trial.

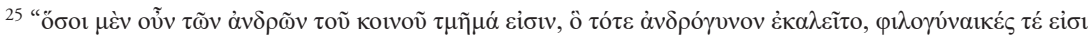

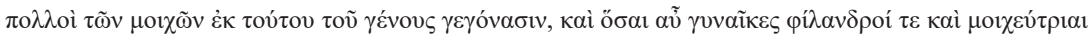

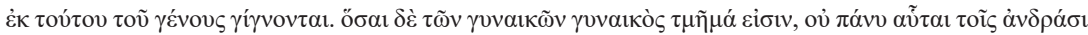

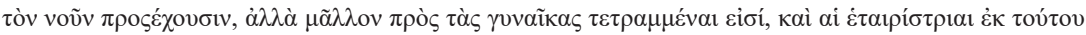

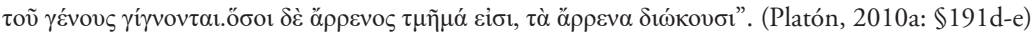




\section{Bibliografía}

Aristóteles. (1995). "Analíticos segundos”. En Tratados de Lógica (Organon II) (Miguel Candel Sanmartín, Trad.) (pp. 301-440). Madrid: Gredos.

Bourdieu, Pierre. (1999). La dominación masculina (Joaquín Jordá, Trad.). Barcelona: Anagrama.

Chernis, Harold F. (1993). El enigma de la primera academia (Susana Marín Delgado, Trad.). México: unam.

De Beauvoir, Simone. (2016). El segundo sexo (Juan García Puente, Trad.) México: Penguin Random House.

Disxaut, Monique. (2013). "L’idée du bien à sa lumière”. En Monique Disxaut, Anissa Castel Bouchouchi, Gilles Kévorkian (Comp.), Lectures de Platon (pp. 67-86). Paris: Ellipses.

Kirk, Geoffrey S.; Raven, John E.; y Schofield, M. (1977). Los filósofos presocráticos (Jesús García Fernández, Trad.). Madrid: Gredos.

Platón. (2010). Diálogos III. Fedón. Banquete. Fedro (Carlos García Gual, Trad.). Madrid: Gredos.

Platón. (2010). “Crátilo”. En Diálogos II. Gorgias. Menéxeno. Eutidemo. Menón, Crátilo (J. L. Calvo, E. Acosta Méndez, E. J. Olivieri y J. Calonge Ruiz, Trads.) (pp. 339-461). Madrid: Gredos.

Platón. (2010). Diálogos V. Parménides. Teeteto. Sofista. Politico (Néstor Luis Cordero, Trad.). Madrid: Gredos.

Platón. (2010). “Timeo”. En Diálogos VI. Filebo. Timeo. Critias (Francisco Lisi, Trad.) (pp. 125-262). Madrid: Gredos.

Platón. (2010). Diálogos VIII. Leyes (Libros I-VI) (Francisco Lisi, Trad.). Madrid: Gredos.

Ross, David. (1993). Platón y la teoría de las ideas (José Luis Diez Arias, Trad.). Madrid: Cátedra.

TaYlor, Alfred. E. (1911). Varia socratica. Oxford: James Parker \& Co.

Vlastos, Gregory. (1982). "The Socratic Elenchus”. Journal of philosophy, 79(11), 711-714. doi: https://doi.org/10.2307/2026548 